\section{Physiology of the Salivary Glands}

A. S. V. BURGEN, M.D.(LOND.), M.R.C.P., and N. G. EMMELIN, M.D.(LUND). Pp. vii +279 , illustrated. Monographs of the Phys. Soc., No. 8. London: Edward Arnold. 1961. 35s.

This monograph written by the Professors of Physiology at the McGill University, Montreal, and at the University of Lund, covers with a wealth of detail the physiology as well as the anatomy and the pharmacology of the salivary glands. Each of the authors has written seven chapters. These are well co-ordinated and the text is largely free of repetitions. As befits the joint effort of authors who belong to different medical traditions, the monograph is remarkable for the truly international body of research which has been considered. Extensive lists of references are given at the end of each chapter. A consequence of this arrangement is that quite a number of publications has to be listed more than once.

A very readable historical introduction reminds us how often observations on salivary glands promoted understanding of much wider areas of physiology. In the chapter on the anatomy of the glands, the reader is given some morphological evidence for later claims for the secretory function of the salivary ducts. The illustrations of the peculiar features of the blood supply of salivary glands, and of the ultra-structure of their cells, are very instructive. The subsequent chapters deal with subjects to which the authors have made numerous important contributions. Such active engagement inevitably influenced the perspective with which the field has been presented. Professor Emmelin discusses the innervation and the effects of denervation of the glands, their pharmacology, spontaneous salivary secretion, and the relationship between the glandular blood supply and the production of saliva. Work on the organic and inorganic components of saliva, and on the metabolism of the glands, is considered by Professor Burgen.

To this reviewer the most stimulating chapter of the book is that on the theories on salivary secretion. In it Professor Burgen opposes with elegant experimenting and bold deduction "the deeply entrenched prejudice about salivary secretion that the acini are the main or sole begetters of the secretion'. In favour of secretory functions of the duct cells argue electrophysiological studies and salivary rest transients, i.e. the phenomenon that after a rest the first saliva secreted on stimulation may contain for I to $2 \mathrm{~min}$. very high concentrations of potassium and iodine. The different time-courses of the outflow of isotopes after their close arterial injection have been studied and translated entirely into spatial differences in the sites at which the isotopes cross from blood into saliva. Interpreted in this way-and combined with other work- these studies allow one to distinguish in the ducts several functionally different regions in which selective secretion and reabsorption may occur.

This monograph has the appeal which scientific literature achieves only when written with authority and enthusiasm. Owing to its clear design, this book will serve equally well those who turn to it for reference on specific points and those who read it for a thorough introduction into the field.

\section{Experimental Immunochemistry}

Elvin A. Kabat, PH.D., with Chapters by Manfred M. MAYER, PH.D. Second edition. Pp. xii +905 , illustrated. Springfield, Illinois: Charles C Thomas. Oxford: Blackwell. 196r. £io i2s.

A familiar object in any immunological laboratory is a faded red volume with dog-eared pages marked here and there with peculiar brown stains-Kabat and Mayer's 'Immunochemistry'. Its usual sorry condition is a good indication of its value as a bench book, 馬t just a prestige item for the library.

Dr. Kabat has taken the opportunity of a sabbatizal in Paris-between his activities of perfecting his Fren $h$ and identifying all the really good restaurants on the Left Bank-to produce a second and much enlarged edition, including as before a long but entirely rewrittin chapter on complement (in itself a valuable small monograph on the subject) and one other by Dr. Mayer. The incorporation of vast amounts of new work, both $\Phi_{n}$ immunology proper and in biochemical technique which has appeared during the last decade has mean $\mathrm{a}$ great increase in size and also, unfortunately, in priçe, but the book is now completely up to date and its vame is correspondingly enhanced.

Those who have the first edition will remember that it contains a discussion of immunological principles critique of methods used, a section devoted to tectsniques and one, by no means the least useful, of recipes for a number of preparations. Although virtually evey chapter seems to have been largely rewritten and others added, the same scheme appears here.

The first two sections take up a little over half the book and comprise a complete textbook of chemical immunology. They are written with the clarity, and with that emphasis upon precise quantitative techniqu $\overrightarrow{\mathrm{G}}$ where they are applicable, which we have come to expect from the author. The adjective chemical ois necessary: no attempt is made to treat in detail the wide and complex (and horribly non-quantitative) fiela s of the cytology of antibody production, the strictly cellular phenomena of hypersensitivity and immunopathology in general, and biochemicogenetic theories ${ }^{\circ} \mathrm{f}$ antibody production. These subjects are not en Eirefy omitted; indeed, they are concisely discussed, with a useful section on techniques of cell transfer. BPt to treat them on a scale commensurate with their if portance in modern biology and medicine waxd demand a book nearly as large as this one, which?1: Kabat has been wise enough not to attempt, though I believe we may expect from others an experimental immunopathology in due course. The treatment of te complex subjects of inhibition and cross-reactivity, wh the light which such studies throw upon the basic structure of antigenic molecules and by extension upon that of the antibody itself, lays understandable emphasis upon work with polysaccharides, where the identificatign of the real determinant group is so much simpler than with protein antigens, though the latter are perhaps mofe interesting biologically.

In the strictly technical sections paper, column and ion-exchange chromatography are efficiently treated, and even the extremely recent molecular sieve techniquies using sephadex are included. Gel-diffusion methods arte also fully dealt with, though I feel that their possibilities for the very rapid and simple quantitative estimation of proteins in complex mixtures like serum is rather underrated. There are short but adequate chapters on eqQilibrium dialysis, radioactive tagging, viscosity, the extraction of bacterial antigens; in fact, I can think $\frac{1}{0}$ only two physico-chemical techniques which one colfld possibly need which are not either described in fullnor at least mentioned together with appropriate references for further information. The two exceptions are light scattering (results by this method are quoted in the text, but it is not discussed in principle in the technical sectiót) and osmometry: in both cases the availability of improved instruments in recent years may increase their potential value and merit their inclusion in a third edition. Amo rag the preparations in the last section.there is less alteration, though all the newer techniques are included; an addition which might be useful in the future would be the 
preparation and characterization of ferritin for electron microscopic studies.

Reviewers normally delight to irritate authors by quoting with a slightly superior air of helpfulness a list of minor misprints and misstatements. Maddeningly enough, although $I$ have hunted for something of the sort for more time than I can afford, I have failed to spot any, though I cannot believe that in a book of this size there are not a few.

The price is rather shattering, though it does not sound so much when quoted as 30 dollars. Despite this the book is absolutely essential as a bench book for any laboratory doing fundamental research using immunological methods and very valuable as a reference book for any biochemical or pathological laboratory where such techniques may be needed from time to time, and nowadays their use is becoming more and more fashionable all the way from botany to biophysics.

\section{Relief of Symptoms}

Walter Modell, M.D., F.A.C.P. Second edition. Pp. $354+$ index. St. Louis: The C. V. Mosby Company. London: Henry Kimpton. 196r. 86s.

In principle, a volume devoted to the relief of symptoms is admirable, and the best way to discuss its value is to put it into daily use, turning constantly to it for guidance. Indeed, it is the author's declared intention that it should be a practical guide to the problems of providing the patient with relief from distress. In order to succeed, such a guide and companion should have a first-rate index, the minimum of verbosity, skilfully constructed charts to equate various symptoms with their means of relief, and it should, of course, be up to date. This book is deficient in some measure in all these respects. The relief of liver dysfunction in the chapter on unconsciousness is dismissed in the fullblown sentence 'Diet and nutrition would seem to have a bearing, but there is no uniformity of opinion on which elements in diet spare the liver, which support it, and which stimulate it, and it is certain that no matter how one feeds the patient, orally or parenterally, he will be going counter to the advice of one expert or another'. It is well known that methyltestosterone and norethandrolone can provide dramatic relief of the intolerable pruritus associated with jaundice, but this does not appear to be the author's experience. Those who would wish to consult the book for advice in the management of one of the most painful conditions of man, orchitis, would do so in vain; neither is it possible to find the relief of post-herpetic neuralgia, renal or biliary colic, or photophobia and blurred vision due to uveitis. It is possible that the principles enunciated under the long chapter on pain are intended to cover all such contingencies. Spironolactone is mentioned in one sentence and no reference is made of its combined use with chlorothiazide for the relief of resistant œdema.

With a less discursive style of writing it could be made a more comprehensive, shorter and less expensive book to cover one of the most important aspects of medicine.

\section{Uveitis and Toxoplasmosis}

E. S. Perkins, Ph.D., M.D., F.R.C.S. Pp. vi +142 + index, illustrated. London: J. \& A. Churchill. 1961. 30s.

Professor Sorsby has estimated that uveitis is the cause of blindness in $2.5 \%$ of all blind persons in England and in $8.3 \%$ of those in the fourth decade.

During the last few years a special Uveitis Clinic in the Institute of Ophthalmology, London, has been accumulating data on the problem, and its results are now reported in detail. The analysis is based on the case records of 1,718 patients, most of whom have been referred to this special clinic from the out-patients' clinics of Moorfields Hospital. The material is classified into anterior, posterior and generalized uveitis and further subdivided into acute and chronic. The cause of the inflammation in each of these categories is analysed and certain generalizations emerge. Acute anterior and generalized uveitis are associated with chronic prostatitis, Reiter's syndrome, ankylosing spondylitis, sacro-iliitis and plantar fasciitis; chronic anterior uveitis is associated with heterochromic cyclitis; and toxoplasmosis appears to be the commonest cause of acute posterior uveitis. Sarcoidosis seems to be sprinkled throughout most groups; it comprises $3.2 \%$ of the whole series, but its incidence varies from I I \% of patients with chronic generalized uveitis to $1 \%$ of women or nil in men with chronic posterior uveitis. In most instances its clinical appearance is not characteristic, and the diagnosis of ocular sarcoidosis is established by evidence of the disease elsewhere, chest radiographic abnormalities, and by means of the Kveim test. The diagnosis of toxoplas mic uveitis was likewise indistinct until the present survey, but largely as a result of the author's pioneer work it is now clinically recognizable as a focal choroiditis involving the posterior half of the fundus, particularly near the disc, the macula and the main retinal vessels.

It is depressing to realize our ignorance concerning the atiology of uveitis. The results of this survey emphasize present limitations of knowledge and point the way to further studies, including the currently fashionable concept of auto-immunity. It is hoped that further investigations will be planned and executed in the same admirable manner as the present survey.

This monograph is essential reading for all postgraduate students in ophthalmology, and is also strongly recommended to all general physicians since uveitis is but one facet of a general disease.

\section{Psychosomatic Aspects of Pædiatrics}

Study Group of the Society for Psychosomatic Research held at the Royal College of Physicians in May, 1959. Edited by RoNALD MAcKEITH and Joseph SANDler. Pp. xiii + r 55. Oxford, London,

New York and Paris: Pergamon Press. I96r. 50s.

This book should be carefully studied by all children's doctors who, to use contemporary jargon, are psychiatrically orientated. Today, as the incidence of organic disease in the young declines, there is a growing awareness amongst pædiatricians of the relatively increasing role played by emotional factors in the causation of children's illnesses. At the same time there must often be a feeling of inadequacy on the physician's part when dealing with such cases because past medical training, with its scant regard for the psychological implications of ill health, has left many of the present generation of doctors ill equipped to deal with psychosomatic problems. Doubtless, Ronald MacKeith and Joseph Sandler, the organizers of the Study Group and co-editors of this report, had all this very much in mind when they conceived the idea of this meeting, arranged an outstanding programme and invited an audience predominantly composed of children's specialists.

Of particular interest to the clinician will be the papers on constipation and encopresis and on recurrent pains in childhood, the lucid account of identification by Sandler and the chapter reporting the sessions at which Miss Anna Freud answered brilliantly a wide range of questions from the pædiatricians in the audience. Other matters discussed and recorded in this 